\title{
Efficient Architectural Assessments
}

\author{
Venkata Swamy Bathina \\ Senior Technical Architect \\ IGATE Global Solutions \\ 158-162(P) and 165(P)-170(P), EPIP Phase II, \\ Whitefield, Bangalore 560 066, India
}

\begin{abstract}
Architectural assessments in any organization plays very critical role, as all the applications must go through the architectural assessment either formally or informally ensuring that the specified architecture suits for the project environment or not.

Unless we specify rationale to the defined architecture whether it's going to work or not, it would be difficult for the project teams to get the required buy-in from all the stakeholders, thus Architecture Assessments in today's Agile Business World are very crucial.

Organizations are going through rough phase in identifying how to ensure a given architecture is perfect or not. Enterprises are struggling on how to set up an architecture assessment team or an architecture governance team, the stages that they need to check for architecture's validity, even after implementation how to make sure the architecture is in compliant with the enterprise architecture that is defined, so that the next process/projects can kick start accordingly, so as to be sure about the compliance with Enterprise Architecture. How effectively can we identify the Risks and mitigation strategies? So that the cost and time can be saved, avoiding lot of re-work due to mistakes in the architecture. To identify any gaps in the architecture at very early stages and to suggest the corrective measures so we can execute the project smoothly, saving lot of resources.

This paper elaborates on directing efficient architectural assessments in an agile business environment, the features, techniques and benefits by efficient architectural assessments in any enterprise and clear methodology in accomplishing the same efficiently, so the organizations can benefit from these architectural assessment engagements by saving huge cost and time ensuring high quality in executing the projects in a complex business world.
\end{abstract}

\section{Keyword}

Architectural assessments, Architecture governance, Security

\section{CURRENT INDUSTRY CHALLENGES}

Currently Organizations are facing the following challenges in the architectural assessment region, as they are not very clear on:

- How to go about architectural assessment process

- How to setup an architectural assessment team or an architecture governance team

- The benefits of architecture assessment engagements

- What are the key attributes to be considered while executing the architectural assessments
- How to select efficient tools

- How to make sure the selected technologies works fine for the given requirements

- Stage Gates for doing the architectural assessments

- $\quad$ Missing View points

- Making sure that the system is in alignment with Enterprise Architecture

- $\quad$ Risk identification and mitigation strategies

- $\quad$ Ensuring the Compliance with legal, legislative and regulatory requirements

- Business Architecture Compliance

- Data Architecture Compliance

- Application Architecture Compliance

- Technology Architecture Compliance

- How to be sure that the given architecture works for them or not

- Post implementation compliance assessments

- After implementation how to make sure it is in compliance with the To-be architecture that is defined, so that the next process can kick start accordingly.

As many project teams are unclear on these aspects it's challenging for them to appreciate the importance of the architectural assessments' role in making the projects successful. Fetching business benefits from the delivery standpoint and architectural development will become much faster resulting in saving overall project time and cost by executing Efficient Architectural Assessments. Aligning the projects to the Enterprise Architecture model defined and at the same time saving lot of cost, time and deliver the projects with highest quality ensuring high level of customer satisfaction.

\section{EFFICIENT ARCHITECTURAL ASSESSMENTS: PROPOSED APPROACH}

Architectural landscape has changed recently with lot of frameworks coming in these days as some of the architectural issues that we were worried in earlier days are being taken care of within those frameworks' design itself. However there are still so many other areas that we need to look from the business principles to architectural principles such as Business, Data, Applications and Technology aspects covering the entire Business and IT landscape. 
In order to address these challenges, the best approach would be to follow the proposed procedure as below, so we can efficiently accomplish the architectural assessments.

\subsection{Efficient Architecture Assessments}

Architectural assessments can happen in the following ways primarily:

- Using Experience based reasoning to assess the Architectures

- Using the tools in assessing the architecture which can address all the non-functional requirements based on their priority and weightage, Architectural Trade off analysis, Checklist based Risk Assessment and any of the quantitative and qualitative approach based tools that will aid in the evaluation process can be leveraged in order to assess the architectures efficiently.

- Typical architecture domains that need to be evaluated thoroughly are as below:

- Business Architecture: All the functional features of the corporate and the execution models, Comprising business principles, business objectives, business functions or capabilities, business processes and roles etc. Focus on Business architecture as many a times assessors tend to ignore the business architecture while they focus mainly on the technology. Thorough study and understanding of the business at least for that particular project will help to gain clear insight on the business functionality and accordingly we can propose the architecture that best suits that business environment. Evaluate Business Interaction, Product Life Cycle, Business Use-Cases, and Process/Event flow to get the complete understanding on the business architecture.

- Data Architecture: Description of data entities and their mapping to the business. Database design, architecture and Data model at the lowest level of granularity can give lot of information on the data flow of the system and the typical system flow providing clear insight of the functionality based on its data. Focusing on the Logical Data Model, Data Security, Data Integrity, Data Migration and Data Life Cycle provides an idea on the kind of database systems that are needed for the given application.

- Application Architecture: The orchestration of application components and how they interact with each other and with the users. The structure and modularization of application software components. Need to focus on Interfaces, Interface Definitions, Gap Analysis, Application Interaction, Communication, Software Distribution, Engineering and Application migration. Evaluate software architecture at the lowest level of granularity gaining more insight into the application architecture.

- Technology Architecture: The focus is on the capacity planning and the kind of hard ware/ software that would need and the structure and behavior of the technology infrastructure can be verified. Evaluate Tools and Technology Standards, Environment and Deployment strategies, Platforms, Networking/Hardware Configuration specifications, Communications Engineering, the infrastructure services they offer to applications, the protocols and networks that connect applications and nodes etc.,

\subsection{Setting up the Architecture Governance Team or the Architecture Assessment Team}

The Open Group provides excellent framework on setting up the Architecture Governance team or the Architecture Assessment team, which can be customized to each organization's needs.

Essentially the Governance Team / Architectural Assessment Team should bridge the technology and business gaps ensuring the IT system proposed would meet the business requirements. Recommend organization wide tools/technologies such as Analysis tools, Architectural and Design methodologies, Security tools, Testing tools, Development Environment, Coding Standards, Build strategies, Environment Setup, Service management, Performance frameworks etc., which could be part of Enterprise Architecture Repository or Industry best standards.

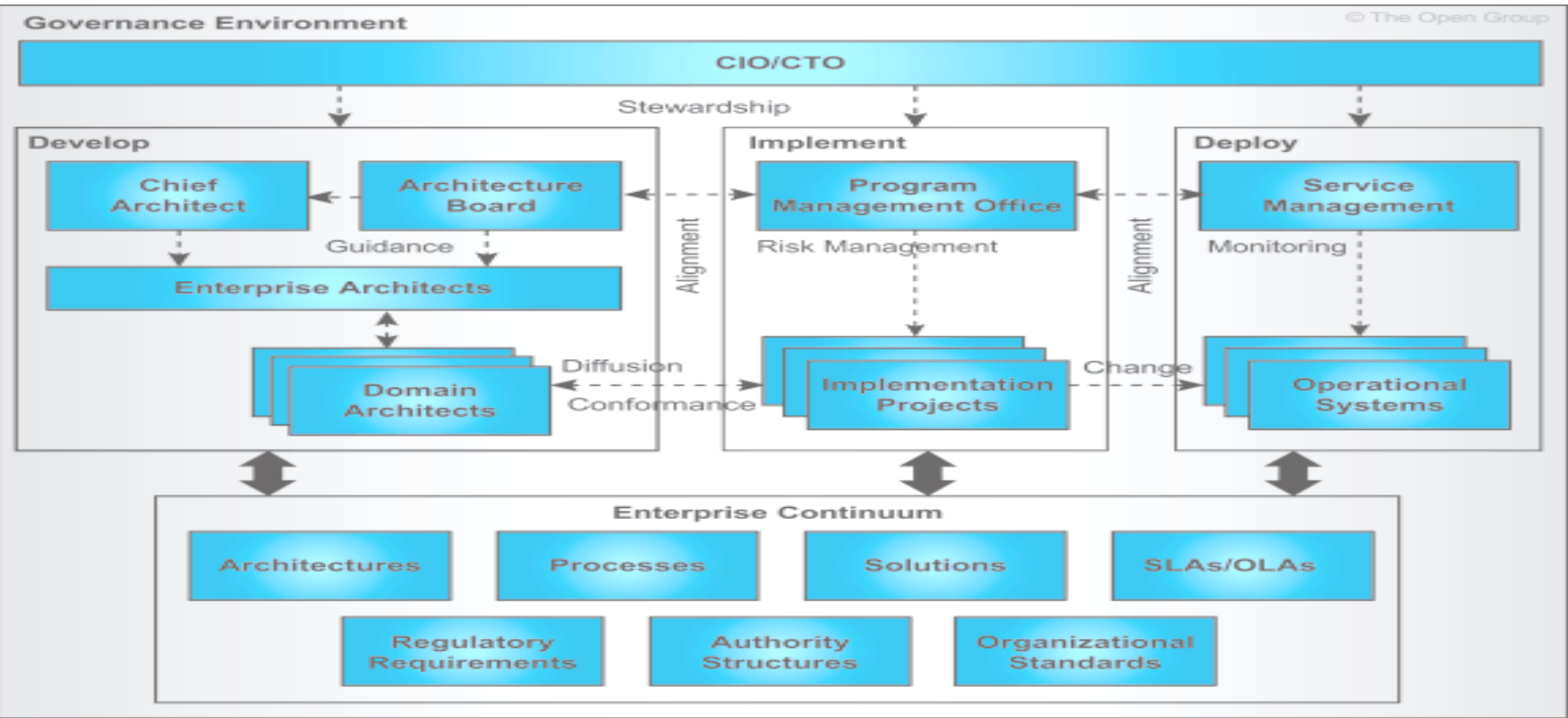


The architectural assessment team constantly accesses the Enterprise Continuum or the Enterprise Architecture Repository in reviewing the architecture to make sure the proposed architecture is in compliance with the Enterprise Architecture defined so as to make sure that the Tools, Technologies, Architectures, Processes, Standards, Regulations, Solutions, Service Level and Operation Level Agreements etc., are in compliant with the proposed
Enterprise Architecture.

\subsection{Quality attributes and Non-Functional Requirements}

Below listed are some of the quality attributes and the nonfunctional requirements that the assessment team should focus on these items for thorough review as these elements play very critical role in the systems architecture.

\section{Quality attributes and Non-Functional Requirements}

\begin{tabular}{|c|c|c|c|c|}
\hline Accessibility & Accountability & Accuracy & Adaptability & Administrability \\
\hline Affordability & Agility & Audit And Control & Autonomy & Availability \\
\hline Backup & Capacity & Certification & Compatibility & Compliance \\
\hline Composability & Configurability & $\begin{array}{l}\text { Configuration } \\
\text { Management }\end{array}$ & Correctness & Credibility \\
\hline Customizability & Debugability & Degradability & Demonstrability & Dependability \\
\hline Deployability & Determinability & Disaster Recovery & Discoverability & Distributability \\
\hline Effectiveness & Efficiency & Emotional Factors & $\begin{array}{l}\text { Environmental } \\
\text { Protection }\end{array}$ & Escrow \\
\hline Evolvability & Exploitability & Extensibility & Failure Management & Failure Transparency \\
\hline Fault-Tolerance & Fidelity & Flexibility & Inspectability & Installability \\
\hline Integrity & Interchangeability & Interoperability & Learnability & Legal and Licensing \\
\hline Maintainability & Manageability & Mobility & Modifiability & Modularity \\
\hline Network Topology & Open Source & Operability & Orthogonality & $\begin{array}{l}\text { Patent-Infringement- } \\
\text { Avoidability }\end{array}$ \\
\hline Performance & Portability & Precision & Predictability & Price \\
\hline Privacy & Process Capabilities & Producibility & Provability & Quality \\
\hline Recoverability & Relevance & Reliability & Repeatability & Reporting \\
\hline Reproducibility & Resilience & Resource Constraints & Responsiveness & Reusability \\
\hline Robustness & Safety & Scalability & Seamlessness & Securability \\
\hline Self-Sustainability & Serviceability & Simplicity & Stability & Standards Compliance \\
\hline Supportability & Survivability & Tailorability & Testability & Timeliness \\
\hline Traceability & Ubiquity & Understandability & Upgradability & Usability \\
\hline
\end{tabular}

\subsection{Architecture Assessment Stage Gates}

Though we are outlining ideal Stage Gates to accomplish architectural assessments, it's not necessary that the architectural reviews should occur in the specified Stage Gate, it could occur in any stage/ ad-hoc or at any major design change. At that particular point in time whatever the inputs that are available, based on those inputs we can complete the architectural evaluation, but it is recommended to initiate the evaluation at the earliest so we can identify and mitigate the risks very early in the projects.
Architecture Review Report typically contains the Identified Risks, Risk mitigation Strategies, Suggestions on industry best standard tools and organization wide tools and technologies, reusable components and any other recommendations useful for the projects. Architecture Review Report is the primary deliverable at the end of each review cycle. 
Stage Gate 1: Inception, Planning

\begin{tabular}{|c|c|c|}
\hline INPUT & Architectural Review Practice & OUTPUT \\
\hline $\begin{array}{l}\text { - RFP and RFI } \\
\text { - SOW } \\
\text { - Project Charter } \\
\text { - As-Is Architecture } \\
\text { - High Level Requirements } \\
\text { Specification } \\
\text { - Technical approach } \\
\text { - Suggestions on Prototyping }\end{array}$ & $\begin{array}{l}\text { - Review the business principles and the business } \\
\text { use cases } \\
\text { - Check for Scope } \\
\text { - Examine if the business is mapped to } \\
\text { Technology appropriately } \\
\text { - Evaluate the feasibility of the solution } \\
\text { - Assess if there are better alternatives to the } \\
\text { tools/technologies suggested } \\
\text { - Identify the risks, gaps and mitigation strategies } \\
\text { - Assess if a Prototype need to be done before } \\
\text { implementing the solution } \\
\text { - Make sure assessment Tools are leveraged } \\
\text { - Review the Life cycle models and its artifacts } \\
\text { - Recommend industry best practices and } \\
\text { Enterprise Architectural Repository tools }\end{array}$ & $\begin{array}{l}\text { - Risk identification and Risk } \\
\text { mitigation strategies } \\
\text { - Recommended Tools and } \\
\text { Technologies } \\
\text { - Architecture Review Report }\end{array}$ \\
\hline
\end{tabular}

Stage Gate 2: Analyze, Architecture and High Level Design

\begin{tabular}{|c|c|c|}
\hline INPUT & Architectural Review Practice & OUTPUT \\
\hline $\begin{array}{l}\text { - Detailed Requirements } \\
\text { Specification } \\
\text { - Functional Requirements } \\
\text { - Non Functional Requirements } \\
\text { - Architecture Definition Document } \\
\text { - High Level Design Document }\end{array}$ & $\begin{array}{l}\text { - Make sure Architectural Principles and Goals } \\
\text { are clearly identified } \\
\text { - Identify and report if there are any errors by } \\
\text { thoroughly reviewing Use Case Diagrams, } \\
\text { Activity Diagrams, Communication Diagrams, } \\
\text { Sequence Diagrams, Interaction Overview } \\
\text { Diagrams etc., } \\
\text { - Evaluate Class Diagrams, Component } \\
\text { Diagrams, Package Diagrams, Deployment } \\
\text { Diagrams, Object Diagrams, Composite } \\
\text { Structure Diagrams, Architectural Views like } \\
\text { 4+1 views (Conceptual, Logical, } \\
\text { Implementation, Component, and Deployment) } \\
\text { are visualized } \\
\text { - Check for NFR compliance } \\
\text { - Leverage Architectural Assessment Tools } \\
\text { - Examine all the segments that describe the } \\
\text { Architecture Definition } \\
\text { - Check the assumptions made are valid or not } \\
\text { - Identify reusable components and assets } \\
\text { - Recommend Organization Best Practices and } \\
\text { Industry Best Practices }\end{array}$ & $\begin{array}{l}\text { - Suggestions and guidelines on } \\
\text { tackling the NFRs efficiently } \\
\text { - Capacity planning advice } \\
\text { - Interfaces communications and } \\
\text { implementation strategies } \\
\text { - Reusable components and assets } \\
\text { - Architecture Review Report }\end{array}$ \\
\hline
\end{tabular}

In each project architecture document, we need to check for the tools/technology selection criteria, essentially to determine the rationale for the particular tool/technology selection. This will also help in appreciating how the proposed technology stack can ensure compliance with the Non Functional Requirements like security, performance, scalability, reliability etc., so we can be sure that the chosen technology stack has proven track record in various implementations. For each tools' selection, there has to be selection criteria mentioned in the architecture definition document as how the tools can really scale, secure, perform and justify in the given environment and the rationale for selection of those tools. 
Stage Gate 3: Low Level Design, Build, Integrate, Test and Deploy

\begin{tabular}{|l|l|l|}
\hline \multicolumn{1}{|c|}{ INPUT } & Architectural Review Practice & OUTPUT \\
\hline - Low Level Design Document & - Review Source Code & $\begin{array}{l}\text { Recommendations to implement and } \\
\text { comply on the Non Functional } \\
\text { Requirements }\end{array}$ \\
- Test Cases & - Apply Assessment Tools & Architecture Review Report \\
- Source Code & - Make sure the suitable design patterns are used \\
- Test Results & - Examine Database Design, Data Model and UI \\
- Deployment Guide & Wire frames & \\
- User Manuals & - Check for NFR compliance and recommend & \\
& industry best practices & \\
\hline
\end{tabular}

Thorough review of source code, test cases and the implementation environments help in making sure that the system will be robust in the specified environment. Any recommendations on the performance improvement and security aspects will be valuable for the project teams as these are the very critical areas where many project teams seek help in.

Post implementation Compliance Review need to be carried out with respect to Enterprise Architecture compliance as part of Architecture Governance.

Stage Gate 4: Post Implementation

\begin{tabular}{|c|c|c|}
\hline INPUT & Architectural Review Practice & OUTPUT \\
\hline $\begin{array}{l}\text { - Complete set of available } \\
\text { Artifacts and Deliverables }\end{array}$ & $\begin{array}{l}\text { - Check the overall scope that is covered in the } \\
\text { implementation so as to ensure that the } \\
\text { system's compliance with the Enterprise } \\
\text { Architecture } \\
\text { - Identify where system fits, in the corporate } \\
\text { framework } \\
\text { - Check how this project will affect other } \\
\text { projects in the organization } \\
\text { - Based on this assessment the next phase or } \\
\text { the subsequent projects can kick start }\end{array}$ & $\begin{array}{l}\text { - Updates to the Enterprise Architecture } \\
\text { Repository } \\
\text { - Architecture Review Report }\end{array}$ \\
\hline
\end{tabular}

\subsection{Architectural Compliance}

\section{Architecture Compliance Assessment/Success}

Measurement-Measure the compliance of the architecture based on how much of the intended architectural aspects are addressed. These measurements will be critical in building momentum for future work.

Below depicted framework from The Open Group, describes the procedure in ensuring the compliance of the system with the proposed architecture.

\section{ARCHITECTURE ASSESSMENT FEATURES AND TECHNIQUES}

Proposing the following significant features and techniques in the architecture assessment practice in ensuring the efficient architectural assessments:
- Leverage experience based reasoning to assess the Architectures by ensuring the center of excellent or the governance team to have suitable resources in evaluation

- Tools such as Architectural Trade off analysis, Checklist based tools would be handy in accomplishing efficient architectural assessments as they would offer quantitative and qualitative rationalization on the validity of the architecture

- Ensure that the Architecture Document would cover all the other deliverables in detail such as Business Flow, Data Management, Application Details, Technology Details and their Interaction etc.,

- Technology stack at the enterprise level need to be in compliance with Organization's Architectural Repository 


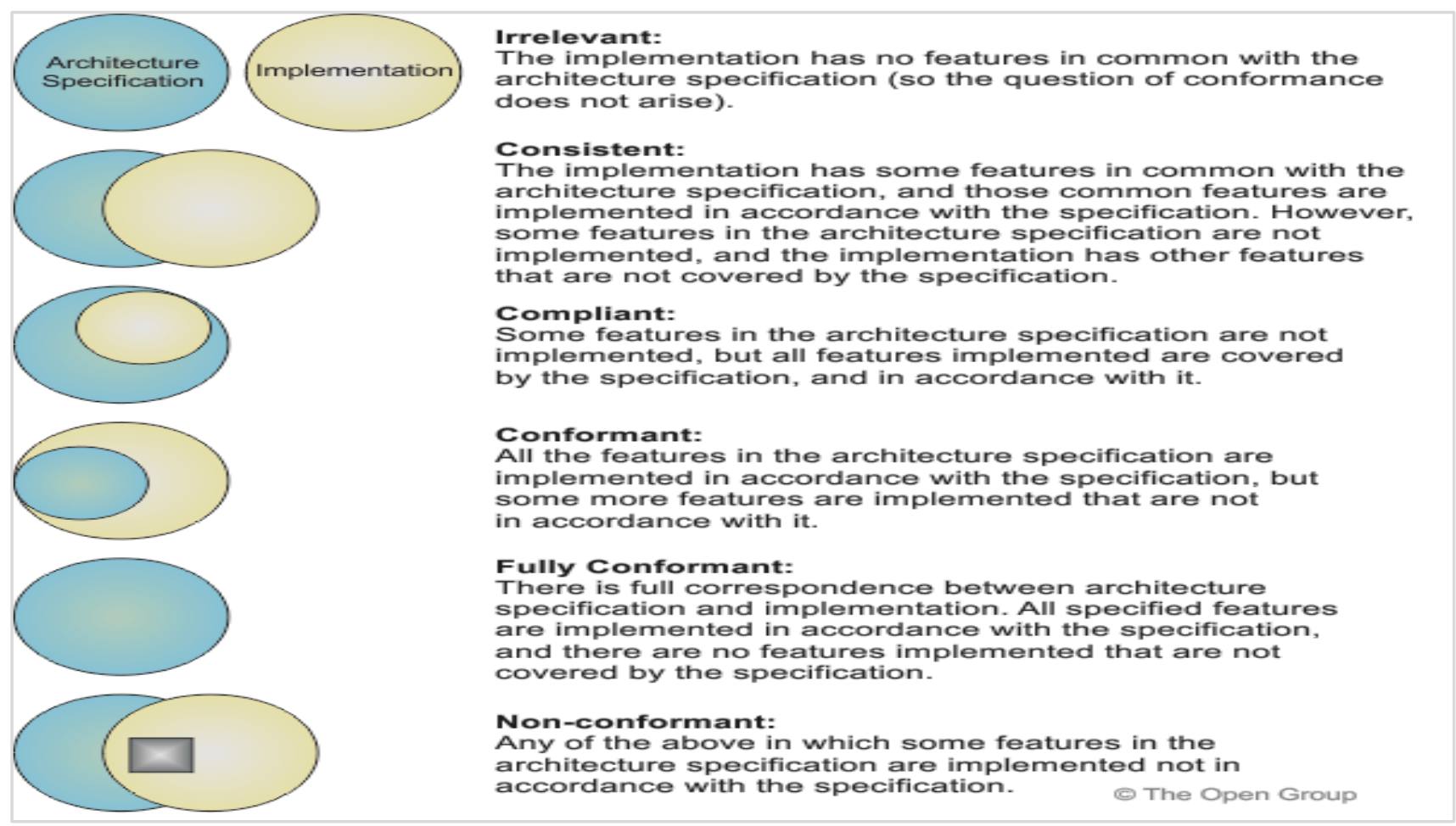

- Ensure Risk factors are clearly identified in the Architecture and the Risk mitigation strategies are appropriately advised

- Easily customizable approach as per the organizations' requirements

- Leverage the knowledge of the talented group of resources where they can be contributing to the success of the projects like a center of excellence

- Continuous update of the checklists and the tools so they will stay current while helping the efficient architectural assessments

- Checklists such as Hardware and Operating System checklist, Software Services and Middleware Checklist, Applications checklist, Application Integration approach, Information Management checklist, Checklists covering all the aspects of software architecture can be leveraged in accomplishing efficient architectural reviews

- Bestow appropriate guidance and support to the project teams so it will be easy for them in completing the projects as they gain more clarity on the system

\section{CONCLUSION}

In conclusion it is very essential for every organization to adopt to formal Architecture Assessment practice that can be tailored for each organization, essentially conforming that the project architectures are in compliant with the requirements elicited, which can save lot of cost and time for the organizations as the proposed approach in assessing the architectures provides the following benefits:

- Saves lot of cost, time and enriches the quality of software projects

- Identifies Risks upfront and advises the Risk mitigation strategies
- Architectural assessments bring in lot of clarity to the project teams so they can execute the projects with ease

- Architectural Assessments in the specified Stage Gates help in getting buy-in from all the stake holders giving them enough confidence in the solutioning approach

- Enterprise Architecture compliance for the applications/systems

- Decent prospect in identifying the reusable components and assets for the organization

- Suitable process to even correct or update the Enterprise Architectural Repository

- Covers top features and industry best practices for reviewing the Architecture and offering the Industry best practices

- Suits well with in any business / technical environment

- Delivering business value from Efficient Architectural Assessment engagements

- Promotes business strategic planning, focusing on business architecture and defining business outcome metrics, along with IT

- Be open to stakeholders refining, or updating, it to fit their needs, so getting all the stake holders buy-in for the smooth progression of the project gaining every stakeholder's confidence

- Best Returns On the Investment

With numerous benefits, this approach can be tactical and crucial for the success of the projects in the organization while ensuring the compliance of the architectures, and saving lot of cost over runs on the projects. 


\section{ACRONYMS}

\begin{tabular}{|l|l|}
\hline Acronym & Expansion \\
\hline EA & Enterprise Architecture \\
\hline TOGAF & The Open Group Architecture Framework \\
\hline NFR & Non-Functional Requirement \\
\hline RFP & Request for Proposal \\
\hline SOW & Statement of Work \\
\hline RFI & Request for Information \\
\hline IT & Information Technology \\
\hline SDLC & Software Development Life Cycle \\
\hline
\end{tabular}

\section{REFERENCES}

[1] Evaluating a Software Architecture by Paul Clements, Rick Kazman, Mark Klein Date: Dec 6, 2001

[2] Enterprise Architectural Methodology and Framework by the Open Group

[3] Architecture Domain, List of System Quality Attributes and Non-Functional Requirements, Wiki
http://en.wikipedia.org/wiki/Architecture_domain, http://en.wikipedia.org/wiki/List_of_system_quality_attri butes, http://en.wikipedia.org/wiki/Nonfunctional_requirement

[4] Architecture Evaluation and Review Practices, Denise Cook June 2007, Updated December 2007

\section{AUTHOR'S PROFILE}

Venkata Swamy Bathina is a Senior Technical Architect in Research \& Innovation team of IGATE; with 17+ years of experience on Software Engineering this includes Enterprise Architecture, Solution Architecture, Application Design \& Development, Delivery Management and Technology Solutions. Venkat holds a Master's Degree in Computer Applications and is a TOGAF certified Enterprise Architect. He has authored numerous papers on various Technology and Business domains. He has extensive experience in Enterprise Web Applications, Enterprise Integration projects, Business Intelligence frameworks using Java/ J2EE technologies. As part of technology strategy, he played instrumental role in defining SOA Strategy, Reference Architecture and Integration Strategy Definition using Sun JCAPS SOA Suite. $\mathrm{He}$ architected multi-tiered applications and Business Application Systems for various customers in USA, Europe, Middle East and APAC regions. 